JEEP 2011, 00008 (2011)

DOI: $10.1051 /$ jeep/201100008

C) Owned by the authors, published by EDP Sciences, 2011

\title{
Thermodynamic description of the Gallium-Lanthanum binary system
}

\author{
M. Idbenali ${ }^{1}$, C.Servant ${ }^{2}$
}

${ }^{1}$ Lycée Hoummane Elftwaki, Dcheira, Agadir, Maroc.

${ }^{2}$ Laboratoire de Physicochimie de l'Etat Solide, ICMMO, Université de Paris-Sud, 91405 Orsay Cedex, France.

\begin{abstract}
Until now, no thermodynamic calculation has been done for the Ga-La system In the present work, it has been evaluated by means of the Calphad approach The solution phases (Liquid, $(\alpha \mathrm{La})$, $(\beta \mathrm{La})$ and $(\gamma \mathrm{La}))$ were modelled with the sublattice formalism and the excess term of the Gibbs energy with the Redlich-Kister equation. The intermetallic compound $\mathrm{Ga}_{2} \mathrm{La}$ which has a homogeneity range, was treated as the formula $(\mathrm{Ga}) 0.667(\mathrm{Ga}, \mathrm{La}) 0.333$ by a two-sublattice model with $\mathrm{Ga}$ on the first sublattice and $\mathrm{Ga}$ and $\mathrm{La}$ on the second one. $\mathrm{Ga}_{6} \mathrm{La}, \mathrm{Ga}_{4} \mathrm{La}, \mathrm{GaLa}, \mathrm{Ga}_{3} \mathrm{La}_{5}, \mathrm{GaLa}_{3}$ have been treated as stoichiometric compounds. The calculated phase diagram and the thermodynamic properties of the system are in satisfactory agreement with the experimental data.
\end{abstract}

\section{Introduction}

The gallium-lanthanum system is a border of some ternary systems interesting for opto-electronics such as Ga-La-S [1]. A recent assessment of the Ga-La system by Palenzona and Cirafici [2] is based on the 31 original references. The same phase diagram was reproduced by Massalski et al [3], figure 1. The assessed phase diagram is essentially based on the work of [4-7]. The equilibrium phases are: (1) the liquid $\mathrm{L}$; (2) the six intermetallic compounds $\mathrm{Ga}_{6} \mathrm{La}, \mathrm{Ga}_{4} \mathrm{La}$ [8-10], $\mathrm{Ga}_{2} \mathrm{La}$ with a homogeneity range ( $\varepsilon$ region), GaLa, $\mathrm{Ga}_{3} \mathrm{La}_{5}$ and $\mathrm{GaLa}_{3}$; and (3) the four terminal solid solutions (Ga), $(\alpha \mathrm{La})$, $(\beta \mathrm{La})$ and $(\gamma \mathrm{La})$ with negligible solubilities. The crystals structure of the various phases of the Ga-La system are reported in Table 1

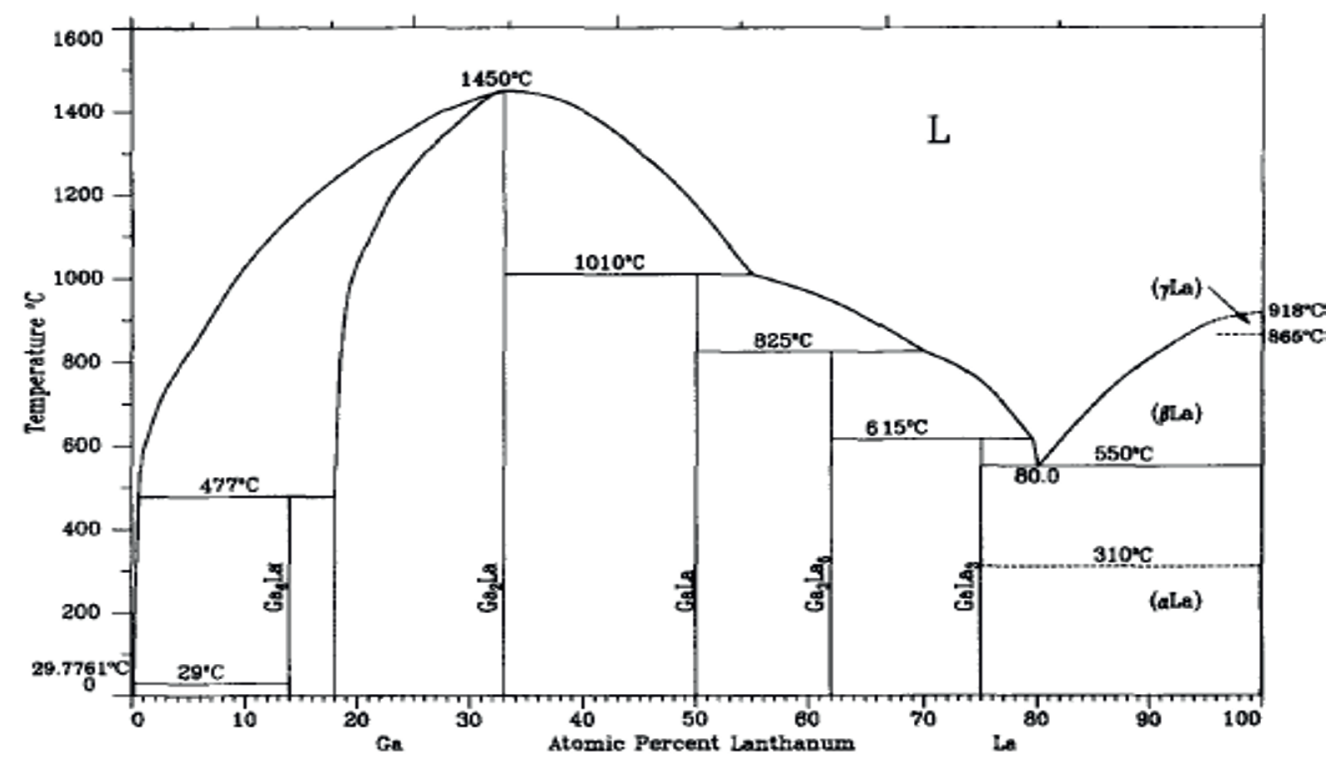

Fig. 1. The Ga-La phase diagram drawn by Palenzona and Cirafici [2]. 


\section{Review of experimental data}

Yatsenko [4] and Yatsenko et al [5] investigated the GaLa equilibrium phase diagram by means of thermal analysis, microscopy, and X-ray diffraction. The resulting phase diagram showed four intermetallic phases $\mathrm{Ga}_{2} \mathrm{La}$ (congruent melting at $1450^{\circ} \mathrm{C}$ ), GaLa, $\mathrm{Ga}_{3} \mathrm{La}_{5}$, and $\mathrm{GaLa}_{3}$ (peritectic formation at $1010^{\circ} \mathrm{C}, 825^{\circ} \mathrm{C}$, and $615^{\circ} \mathrm{C}$ respectively). There were also two eutectics
$\mathrm{Liq} \Leftrightarrow \mathrm{Ga}_{6} \mathrm{La}+(\mathrm{Ga})$ at $30^{\circ} \mathrm{C}$ and $\mathrm{Liq} \Leftrightarrow \mathrm{GaLa}_{3}+(\beta \mathrm{La})$ at $550^{\circ} \mathrm{C}$ and about 80 at.\% La. To describe the eutectic on the Ga-rich side, [4] and [5] used the term "degenerate," presumably because the solidus temperature does not differ significantly from

Table 1. Symbols and crystal structures of the solid phases in the La-Ga alloys

\begin{tabular}{|c|c|c|c|c|c|c|}
\hline $\begin{array}{l}\text { Diagram } \\
\text { Symbol }\end{array}$ & $\begin{array}{c}\text { Composition at } \\
\text { \%La }\end{array}$ & $\begin{array}{c}\text { Symbol used in } \\
\text { Thermo-Calc Data } \\
\text { File }\end{array}$ & $\begin{array}{l}\text { Pearson } \\
\text { symbol }\end{array}$ & Space group & $\begin{array}{l}\text { Struktur-bericht } \\
\text { Designation }\end{array}$ & Prototype \\
\hline$\alpha \mathrm{Ga}$ & 0 & $\begin{array}{c}\text { ORTHORHOMBIC } \\
\text { GA }\end{array}$ & $o C 8$ & Cmca & All & $\alpha \mathrm{Ga}$ \\
\hline $\mathrm{Ga}_{6} \mathrm{La}$ & 14.29 & Ga6La & $t P 14$ & P4/nbm & & $\mathrm{Ga}_{6} \mathrm{Pu}$ \\
\hline $\mathrm{Ga}_{4} \mathrm{La}$ & 20 & Ga4La & $o P 20$ & Pmmm & & \\
\hline $\mathrm{Ga}_{2} \mathrm{La}$ & 18 to 33.3 & $\mathrm{Ga} 2 \mathrm{La}$ & $h P 3$ & $P 6 / \mathrm{mmm}$ & C32 & $\mathrm{AlB}_{2}$ \\
\hline $\mathrm{GaLa}$ & 50 & $\mathrm{GaLa}$ & $o C 8$ & $\mathrm{Cmcm}$ & $B f$ & $\mathrm{CrB}$ \\
\hline $\mathrm{Ga}_{3} \mathrm{La}_{5}$ & 62.5 & Ga3La5 & $t I 32$ & $I 4 / \mathrm{mcm}$ & $D 8 r$ & $\mathrm{Cr}_{5} \mathrm{~B}_{3}$ \\
\hline $\mathrm{GaLa}_{3}$ & 75 & GaLa3 & $c P 4$ & $P m \overline{3} m$ & $\mathrm{Ll}_{2}$ & $\mathrm{AuCu}_{3}$ \\
\hline$\gamma \mathrm{La}$ & 100 & $\mathrm{BCC}$ & $c I 2$ & $\operatorname{Im} \overline{3} m$ & $A 2$ & W \\
\hline$\beta \mathrm{La}$ & 100 & FCC & $c F 4$ & $F m \overline{3} m$ & $A 1$ & $\mathrm{Cu}$ \\
\hline$\alpha \mathrm{La}$ & 100 & DHCP & $h P 4$ & $\mathrm{P} 63 / \mathrm{mmc}$ & $A 3^{\prime}$ & $\alpha \mathrm{La}$ \\
\hline
\end{tabular}

the melting temperature of Ga. [4] reported an accuracy in the temperature determination of $\pm 5^{\circ} \mathrm{C}$. No appreciable solid solubility of $\mathrm{La}$ in $(\mathrm{Ga})$ or $\mathrm{Ga}$ in $(\mathrm{La})$ was observed by [4] and [5], and all the intermediate phases (except $\mathrm{Ga}_{2} \mathrm{La}$ ) appeared to be line compounds. Pelleg et al [6] investigated the Ga-rich side of the Ga-RE systems, finding the $\mathrm{Ga}_{6} \mathrm{La}$ compound. This Ga-rich compound, called $\eta$ phase, is formed by a peritectic reaction $\mathrm{Ga}_{6} \mathrm{La} \Leftrightarrow \mathrm{Liq}+\mathrm{Ga}_{2} \mathrm{La}$ at $\mathrm{T}=477^{\circ} \mathrm{C}$. Dayan et al [7], using interdiffusion studies of lanthanum with gallium, carried out with diffusion couples formed by annealing La metal in liquid $\mathrm{Ga}$ at various temperatures, determined the homogeneity range of $\mathrm{Ga}_{2} \mathrm{La}$ and found it extends on the Ga-rich side from 18 to 33.3 at.\% La. Their study excluded also the possible existence of $\mathrm{Ga}_{3} \mathrm{La}$ as no layer of this composition is present in this system. $\mathrm{Lu}$ et al [11] studied the Ga-rich side of the Ga-La system. They reported that $\mathrm{Ga}_{2} \mathrm{La}$ has an homogeneity range extending from 28.4 to 33.3 at.\% La, which occurs when one La atom is replaced randomly by a pair of $\mathrm{Ga}$ atoms. These authors also fixed the peritectic reaction of formation for $\mathrm{Ga}_{6} \mathrm{La}\left(\mathrm{Liq}+\mathrm{Ga}_{2} \mathrm{La} \Leftrightarrow \mathrm{Ga}_{6} \mathrm{La}\right.$ ) at $477^{\circ} \mathrm{C}$. A critical evaluation of the data available in the literature for the Ga-La system has been reported by Palenzona and Cirafici [2]. They made the assessment of the phase diagram principally on the basis of the experimental investigation carried out by [4-7]. In their work, Dayan et al [7], studied samples prepared at $600^{\circ} \mathrm{C}$ and around 80 at. Ga content. By differential thermal analysis a phase transformation was observed in the $\varepsilon$ region and by scanning electron micrographs a phase with about 80 at. $\%$ Ga was detected but its crystal structure was not identified. Later on, an analysis of the structure of $\mathrm{Ga}_{4} \mathrm{La}$ was given by Zevin et al [8]. The structure is ordered orthorhombic. Ga pairs assumed ordering positions within the lattice and orientation ordering of the pairs of Ga depends on the Ga concentration. More recently, a new type of phase transformation was proposed by [9, 10]. The $\mathrm{Ga}_{4} \mathrm{La}\left(\varepsilon^{\prime}\right)$ phase was described as a long-range ordered structure with a stoichiometric concentration of 80 at. $\% \mathrm{Ga}$. Due to its definition by the orientation of pairs of gallium atoms the nature of the ordering transition is unique. The ordering temperature is $480^{\circ} \mathrm{C}$. In order to obtain equilibrium state, samples were arccast and then vacuum annealed and homogenized at $600^{\circ} \mathrm{C}$ for 72 hours, finally at $480^{\circ} \mathrm{C}$ for 72 hours. As in the earlier works, the homogenization treatments of the samples were carried out at or above $600^{\circ} \mathrm{C}$, and the $\varepsilon$ ' phase was not detected. The enthalpies of formation of the intermetallic compounds of the $\mathrm{Ga}-\mathrm{La}$ system have 
been determined by several authors [12-15]. Vnuchkova et al [12] have measured the standard enthalpies of formation of $\mathrm{Ga}_{2} \mathrm{La}$ by e.m.f, in the $675-975 \mathrm{~K}$ temperature range. De Boer et al. [13] calculated by a semi-empirical model the enthalpies of formation of $\mathrm{Ga}_{3} \mathrm{La}_{5}, \mathrm{GaLa}, \mathrm{Ga}_{2} \mathrm{La}$ and $\mathrm{Ga}_{0.81} \mathrm{La}_{0.19}$. In 2000, Meschel and Kleppa [14] have measured the standard enthalpies of formation of $\mathrm{Ga}_{2} \mathrm{La}$ by high-temperature direct synthesis calorimetry at $1373 \mathrm{~K}$. Recently, Babu et al [15] measured the standard enthalpies of formation of $\mathrm{Ga}_{3} \mathrm{La}_{5}$, GaLa and $\mathrm{Ga}_{2} \mathrm{La}$ by high temperature liquid gallium solution calorimetry. The same authors determined the integral enthalpies of formation of $\mathrm{GaLa}$

alloys at $1125 \mathrm{~K}$ by using precipitation calorimetry and the partial enthalpy of solution of lanthanum in liquid gallium at infinite dilution at $1099 \mathrm{~K}$. Babu et al [1(] confirmed the result of Meschel and Kleppa [14].

\section{Thermodynamic Models}

\subsection{Pure elements}

The Gibbs energy function $(298.15 \mathrm{~K})$ for the element $\mathrm{i}$ ( $\mathrm{i}=\mathrm{La}, \mathrm{Ga})$ in the $\phi$ phase $(\phi=$ Liquid, $\alpha \mathrm{La}(\mathrm{hP} 4), \beta \mathrm{La}$ (cF4), $\gamma \mathrm{La}(\mathrm{cI} 2), \mathrm{Ga}(\mathrm{oS} 8))$ is described by an equation of the following form:

$G_{i}^{\phi}=a+b T+c T \ln T+d T+e T^{3}+f T^{7}+g T^{-1}+h T^{-9}$

The coefficients $a-h$ of the power series of the Gibbs energy of the different phases $\phi$ are taken from the SGTE data set [16].In this paper, the Gibbs energy functions are taken from the SGTE compilation of Dinsdale [16]. These functions are valid up to $\mathrm{T}=4000 \mathrm{~K}$ for $\mathrm{La}$ and $\mathrm{Ga}$.

\subsection{Solution phase}

The liquid phase was modelled as a substitutional solution according to the polynomial Redlich-Kister [17] model. The Gibbs energy of one mole of formula unit of phase is expressed as the sum of the reference part ${ }^{r e f} G$, the ideal part ${ }^{i d} G$ and the excess part ${ }^{e x} G$ :

$$
\begin{aligned}
& G^{l i q}-H^{S E R}={ }^{r e f} G^{l i q}+{ }^{i d} G^{l i q}+{ }^{e x} G^{l i q} \\
& { }^{r e f} G_{l i q}=x_{G a}\left[{ }^{0} G_{G a}^{l i q}-H_{G a}^{S E R}\right]+x_{L a}\left[{ }^{0} G_{L a}^{l i q}-H_{L a}^{S E R}\right]
\end{aligned}
$$

where $H_{i}^{S E R}(298.15 \mathrm{~K})$ is the molar enthalpy of the $i$ element at $298.15 \mathrm{~K}$ in its Standard Element Reference (SER) state, orthorhombic for Ga and hexagonal for La:

$$
{ }^{i d} G_{l i q}=R T\left(y_{G a} \ln y_{G a}+y_{L a} \ln y_{L a}\right)
$$

where $R$ is the ideal gas constant; $T$ is the temperature, in Kelvin; $x_{G a}$ and $x_{L a}$ are the mole fraction of the elements $\mathrm{Ga}$ and La, respectively.

The ${ }^{e x} G_{l i q}$ energy part in Eq. (2) is given by the Redlich-Kister polynomial [17]
${ }^{e x} G_{l i q}=y_{i} y_{j} \sum_{\lambda=0}^{\lambda}{ }^{\lambda} L_{i, j}^{L i q}\left(y_{i}-y_{j}\right)^{\lambda}$

with the $i$ and $j$ indices which correspond to the two species Ga and La.

The binary interaction parameters of the ${ }^{\lambda} L_{i, j}^{L i q}$ type, assessed in the present work, were temperature dependent as follows:

${ }^{\lambda} L_{i, j}^{L i q}=a_{\lambda}+b_{\lambda} T$

$a_{\lambda}$ and $b_{\lambda}$ are the coefficients to be optimized.

The Ga (oS8), $\alpha \mathrm{La}$ (hP4), $\beta \mathrm{La}$ (cF4) and $\gamma \mathrm{La}(\mathrm{cI} 2)$, phases were respectively modelled as pure $\mathrm{Ga}$ and $\mathrm{La}$ because of the unknown and certainly very low solubility of $\mathrm{La}$ in $\mathrm{Ga}$ and $\mathrm{Ga}$ in $\mathrm{La}$.

\subsection{Stoichiometric compounds:}

The Gibbs energy of the stoichiometric compounds is expressed as follows:

$G_{A_{p} B_{q}}=\frac{p}{p+q}{ }^{0} G_{A}+\frac{q}{p+q}{ }^{0} G_{B}+a+b T$

where ${ }^{0} G_{A}$ and ${ }^{0} G_{B}$ are the Gibbs energy of the pure elements $\mathrm{Ga}$ and La respectively; $a$ and $b$ are parameters to be determined.

\subsection{1 $\mathrm{Ga}_{2} \mathrm{La}$ Phase}

The $\mathrm{Ga}_{2} \mathrm{La}$ phase is a C32 Laves phase, isotypic with AlB2. The homogeneity range of $\mathrm{Ga}_{2} \mathrm{La}$ extends between $\mathrm{Ga}_{2} \mathrm{La}$ and the Ga-rich side in the range 18.0 to 33.3 at. \% $\mathrm{La}[2]$ and more recently in the 14.3 to 33.3 at \% $\mathrm{La}$ [10]. The $\varepsilon$ and $\eta$ designations for $\mathrm{Ga}_{2} \mathrm{La}$ and $\mathrm{Ga}_{6} \mathrm{La}$ from [6] were omitted by Palenzona and Cirafici [2]. The $\mathrm{Ga}_{2} \mathrm{La}$ intermetallic compounds was treated as (Ga) $0.667(\mathrm{Ga}, \mathrm{La} \%) 0.333$ by a two sublattice model. The symbol $\%$ denotes the major component in the corresponding sublattice.The Gibbs energy function per mole $(\mathrm{m})$ of the formula unit $(\mathrm{Ga}) 0.667(\mathrm{Ga}, \mathrm{La} \%) 0.333$ is the following:

$G_{m}^{G a 2 L a}=y_{G a}^{1} y_{G a}^{2} G^{G a 2 L a}+y_{G a}^{1} y_{L a}^{2} G^{G a 2 L a}+$
$R T\left[0.333\left(y_{G a}^{2} \ln \left(y_{G a}^{2}\right)+y_{L a}^{2} \ln \left(y_{L a}^{2}\right)\right)\right]+{ }^{e x} G_{m}^{\phi}$

where $y_{G a}^{1}=1$ denotes the site fraction of gallium in the first sublattice, $y_{G a}^{2}$ and $y_{L a}^{2}$ the site fractions of gallium and lanthanum in the second sublattice, ${ }^{0} G^{G a 0.667 G a 0.333}$ is the Gibbs energy of the hypothetical compounds $\mathrm{Ga}_{0.667} \mathrm{Ga}_{0.333}$. ${ }^{0} G^{G a 0.667 L a 0.333}$ is the Gibbs energy of the stoichiometric compound $\mathrm{Ga}_{0.667} \mathrm{La}_{0.333}$. $H_{(G a) 0.667(L a \%, G a) 0.333}^{S E R}=\left(0.667 y_{G a}^{1}+0.333 y_{G a}^{2}\right) H_{G a}^{S E R}(9)$ $\left.+\left(0.333 y_{L a}^{2}\right) H_{L a}^{S E R}\right)$ 
${ }^{e x} G_{m}^{\phi}$ is the excess Gibbs energy expressed by the following expression:

${ }^{e x} G_{m}^{\phi}=y_{G a}^{2} y_{L a}^{2}\left(L_{G a: G a, L a}^{\lambda}\right)$

where $L_{G a: G a, L a}^{\lambda}$ represent the interaction parameters between the elements $\mathrm{Ga}$ and $\mathrm{La}$ in the second sublattice; the first sublattice being only occupied by the element Ga. These excess parameters are temperature dependent as:

$$
L_{G a: G a, L a}^{\lambda}=a_{\lambda}+b_{\lambda} T
$$

In order to avoid the occurrence of the hypothetical compound $\mathrm{Ga} 0.6667 \mathrm{Ga} 0.3333$, during the phase diagram calculation, the value $+5000 \mathrm{~J} / \mathrm{mol}$ of atoms was added to GHSERGa, see Table 2.
Most of the experimental data mentioned in Section 2 were used for the optimization of the thermodynamic parameters. As the first step, the thermodynamic parameters for liquid were optimized based on the integral enthalpies of mixing of the liquid alloys determined by Babu et al [15], using the Thermo-Calc program [18]. The data of the single phase domain (La$\mathrm{Ga}$ ) were used while the ones of the two-phase domain $\left(\mathrm{La}-\mathrm{Ga}+\mathrm{LaGa}_{2+\mathrm{x}}\right)$ were discarded. The compositions of the phases involved in the invariant reactions are mainly based on the phase diagram of the Ga-La system evaluated by Palenzona and Cirafici [2]. For the $\mathrm{Ga}_{2} \mathrm{La}$ phase, the interaction parameters Eq. ((8)-(11)), were adjusted according to the enthalpies of formation measured by Meschel and Kleppa [14] and Babu et al [15]. For the stoichiometric compounds, the interaction parameters Eq. (6) were adjusted according to the enthalpies of formation measured by Babu et al. [15]. All the optimized parameters are given in Table 2.

\section{Assessment procedure}

Table 2. The optimized thermodynamic parameters of the Ga-La system

\begin{tabular}{|c|c|c|}
\hline Phase & $\begin{array}{l}\text { Thermodynamic } \\
\text { model }\end{array}$ & Parameters (units in $\mathrm{J} / \mathrm{mol}$.at and $\mathrm{J} / \mathrm{mol}$ at.K ) \\
\hline Liquid & $(\mathrm{Ga}, \mathrm{La})$ & $\begin{array}{l}{ }^{0} L_{G a, L a}^{L i q}=-236395.138+39.8826274 \mathrm{~T} \\
{ }^{1} L_{G a, L a}^{L i q}=-64504.2950+0.137122278 \mathrm{~T}\end{array}$ \\
\hline $\begin{array}{l}\text { BCC_A2 } \\
\text { FCC_A1 } \\
\text { DHCP } \\
\text { ORTHORHOM } \\
\text { BIC_GA }\end{array}$ & $\begin{array}{l}(\mathrm{Ga}, \mathrm{La})_{1}(\mathrm{Va})_{3}{ }_{3} \\
(\mathrm{Ga}, \mathrm{La})_{1}(\mathrm{Va})_{1} \\
(\mathrm{La}) \\
(\mathrm{Ga})\end{array}$ & $\begin{array}{l}\text { No excess term } \\
\text { No excess term } \\
\text { No excess term } \\
\text { No excess term }\end{array}$ \\
\hline $\mathrm{Ga}_{6} \mathrm{La}$ & $(\mathrm{Ga})_{0.857}:(\mathrm{La})_{0.143}$ & $\begin{array}{l}G_{G a: L a}^{G a 6 L a}-0.857^{298} H_{G a}^{\text {ORTHORHOMBIC_GA }}-0.143^{298} H_{L a}^{D H C P}= \\
-41945.1358+1.05 \mathrm{~T}\end{array}$ \\
\hline $\mathrm{Ga}_{4} \mathrm{La}$ & $(\mathrm{Ga})_{0.8}:(\mathrm{La})_{0.2}$ & $\begin{array}{l}G_{G a: L a}^{G a 4 L a}-0.8^{298} H_{G a}^{\text {ORTHORHOMBIC_GA }}-0.2^{298} H_{L a}^{D H C P}= \\
-55029.1060+3.07 \mathrm{~T}\end{array}$ \\
\hline $\mathrm{Ga}_{2} \mathrm{La}$ & $(\mathrm{Ga})_{0.667}:(\mathrm{La})_{0.333}$ & $\begin{array}{l}G_{G a: L a}^{G a 2 L a}-{ }^{298} H_{G a}^{\text {ORTHORHOMBIC_GA }}=G H S E R G a+5000 \\
G_{G a: L a}^{G a 2 L a}-0.6667^{298} H_{G a}^{\text {ORTHORHOMBIC_GA }}-0.333^{298} H_{L a}^{D H C P}= \\
-77450.7437+3.78135826 \mathrm{~T} \\
{ }^{0} L_{G a: L a, L a}^{G a 2 L a}=-32254.0822+1.24949858 \mathrm{~T} \\
{ }^{1} L_{G a: L a, L a}^{G a 2 L a}=10031.1315\end{array}$ \\
\hline $\mathrm{GaLa}$ & $(\mathrm{Ga})_{0.5}:(\mathrm{La})_{0.5}$ & $\begin{array}{l}G_{G a: L a}^{G a L a}-0.5^{298} H_{G a}^{\text {ORTHORHOMBIC_GA }}-0.5^{298} H_{L a}^{D H C P}= \\
-77742.0789+10.7444362 \mathrm{~T}\end{array}$ \\
\hline $\mathrm{Ga}_{3} \mathrm{La}_{5}$ & $(\mathrm{Ga})_{0.375}:(\mathrm{La})_{0.625}$ & $\begin{array}{l}G_{G a: L a}^{\text {Ga } 2 a 5}-0.375{ }^{298} H_{G a}^{\text {ORTHORHOMBIC_GA }}-0.625{ }^{298} H_{L a}^{D H C P}= \\
-58509.0726+5.015 \mathrm{~T}\end{array}$ \\
\hline $\mathrm{GaLa}_{3}$ & $(\mathrm{Ga})_{0.25}:(\mathrm{La})_{0.75}$ & $\begin{array}{l}G_{G a: L a}^{G a L a 3}-0.25{ }^{298} H_{G a}^{\text {ORTHORHOMBIC_GA }}-0.75{ }^{298} H_{L a}^{D H C P}= \\
-38632+1.8 \mathrm{~T}\end{array}$ \\
\hline
\end{tabular}

* (Va) for vacancy 
Table 3. Invariant reactions in the Ga-La System

\begin{tabular}{|c|c|c|c|c|}
\hline \multirow[t]{2}{*}{ Reaction } & \multicolumn{2}{|c|}{ Palenzona and Cirafici [2] } & \multicolumn{2}{|c|}{ This work } \\
\hline & $\mathrm{T}(\mathrm{K})$ & $x(\mathrm{La})$.at. & $\mathrm{T}(\mathrm{K})$ & $x(\mathrm{La})$ at. \\
\hline $\mathrm{Liq} \Leftrightarrow \alpha \mathrm{Ga}+\mathrm{Ga}_{6} \mathrm{La}$ & 302 & Liq $<0.001$ & 301.7 & Liq 0.005 \\
\hline $\mathrm{Liq}+\mathrm{Ga}_{4} \mathrm{La} \Leftrightarrow \mathrm{Ga}_{6} \mathrm{La}$ & 750 & Liq 0.005 & 748.6 & $\begin{array}{l}\text { Liq } 0.092 \\
\mathrm{Ga}_{2} \mathrm{La} 0.234\end{array}$ \\
\hline $\mathrm{Liq}+\mathrm{Ga}_{2} \mathrm{La} \Leftrightarrow \mathrm{Ga}_{4} \mathrm{La}$ & & & 752.3 & Liq 0.093 \\
\hline $\mathrm{Liq} \Leftrightarrow \mathrm{Ga}_{2} \mathrm{La}$ & 1723 & Liq 0.333 & 1727 & Liq 0.333 \\
\hline $\mathrm{Liq}+\mathrm{Ga}_{2} \mathrm{La} \Leftrightarrow \mathrm{GaLa}$ & 1283 & Liq 0.55 & 1295 & Liq 0.508 \\
\hline $\mathrm{Liq}+\mathrm{GaLa} \Leftrightarrow \mathrm{Ga}_{3} \mathrm{La}_{5}$ & 1098 & Liq 0.70 & 1095 & Liq 0.655 \\
\hline $\mathrm{Liq}+\mathrm{Ga}_{3} \mathrm{La}_{5} \Leftrightarrow \mathrm{GaLa}_{3}$ & 888 & Liq 0.79 & 885.8 & Liq 0.777 \\
\hline $\mathrm{Liq} \Leftrightarrow \mathrm{GaLa}_{3}+\beta \mathrm{La}$ & 823 & Liq 0.80 & 826 & Liq 0.830 \\
\hline $\mathrm{Liq}+\beta \mathrm{La} \Leftrightarrow \gamma \mathrm{La}$ & 1138 & Liq 0.94 & 1134 & Liq 0.9679 \\
\hline
\end{tabular}

\section{Results and discussion}

The thermodynamic optimization of the Gibbs energy parameters is an application of the CALPHAD [19] technique with the PARROT module of the Thermo Calc software [18]. All of the experimental information mentioned in the Section 2 (phase diagram information and thermodynamics) was used for the optimization of the thermodynamic parameters of the different modelled phases. In order to avoid the formation of a unwanted inverted miscibility gap in the liquid phase, additional constraints $\Delta H_{f}$ versus $x(\mathrm{La})$ ranging from 0 to 1 (every $\Delta \mathrm{x}(\mathrm{La})=0.1$ at.) and at different temperatures up to $5000 \mathrm{~K}$ (every $\Delta \mathrm{T}=50 \mathrm{~K}$ ) were therefore imposed on the thermodynamic parameters. All the parameters for the Ga-La system obtained by means of the optimization procedure are listed in Table 2. The resulting binary Ga-La phase diagram, based on the assessment is shown figure 2 together with the data from the literature. The calculated phase boundaries are in good agreement with the experimental data. Table 3 indicates that the temperatures and compositions for all the invariant equilibria in the system are well reproduced. A very good agreement is observed for the temperatures. The agreement is less good for the compositions of the liquid phase. The Ga-rich region of the $\mathrm{Ga}-\mathrm{La}$ phase diagram is plotted in figure 3 . The assessed integral enthalpies of mixing of liquid Ga-La alloys referring to liquid components at $\mathrm{T}=1125 \mathrm{~K}$ are plotted in figure 4. Also shown in this figure are the data by [15]. A good agreement is noted. The enthalpies of formation of the $\mathrm{Ga}-\mathrm{La}$ intermetallic compounds measured and calculated ones are presented in figure 5 and in Table 4. The optimized enthalpy of formation of $\mathrm{Ga}_{4} \mathrm{La}\left(\Delta H_{f}=-55033 \mathrm{~J} / \mathrm{mol}\right)$ is higher than the one determined in $[13,15] \quad(-42700 \mathrm{~J} / \mathrm{mol}$ and -37500 $\mathrm{J} / \mathrm{mol})$..

Table 4. Standard enthalpies of formation of the Ga-La alloys

\begin{tabular}{|c|c|c|c|c|}
\hline Compound & $\begin{array}{l}-\Delta \mathrm{Hf}_{298.15} \\
\mathrm{~kJ} / \mathrm{mol} . \mathrm{at}\end{array}$ & Method & Ref. & $\begin{array}{l}\text { This work } \\
\mathrm{J} / \text { mol.at }\end{array}$ \\
\hline $\mathrm{Ga}_{0.79} \mathrm{La}_{0.21}$ & $\begin{array}{l}37.5 \pm 3.7 \\
42.7\end{array}$ & $\begin{array}{l}\text { Precipit. Calori. } \mathrm{T}=1125 \mathrm{~K} \\
\text { Miedema's model }\end{array}$ & $\begin{array}{l}{[15]} \\
{[13]}\end{array}$ & -41945.1358 \\
\hline $\mathrm{Ga}_{4} \mathrm{La}$ & & & & -55033 \\
\hline $\mathrm{Ga}_{2} \mathrm{La}$ & $\begin{array}{l}69 \pm 3.7 \\
69.2 \pm 2.4 \\
92.0 \pm 0.1 \\
67.5\end{array}$ & $\begin{array}{l}\text { Ga. Soln. Calori. } T=1099 \mathrm{~K} \\
\text { Dir. Syn. Calori. T=1373K } \\
\text { EMF: } 675-975 \mathrm{~K} \\
\text { Miedema's model }\end{array}$ & $\begin{array}{l}{[15]} \\
{[14]} \\
{[12]} \\
{[13]}\end{array}$ & $\begin{array}{l}-72882 \text { for } x(\mathrm{La})=0.3 \\
-53226 \text { for } x(\mathrm{La})=0.202 \\
-50227 \text { for } x(\mathrm{La})=0.19\end{array}$ \\
\hline GaLa & $\begin{array}{l}74.8 \pm 3.7 \\
73.5\end{array}$ & $\begin{array}{l}\text { Ga. Soln. Calori. } \mathrm{T}=1102 \mathrm{~K} \\
\text { Miedema's model }\end{array}$ & $\begin{array}{l}{[15]} \\
{[14]}\end{array}$ & -77746 \\
\hline $\mathrm{Ga}_{3} \mathrm{La}_{5}$ & $\begin{array}{l}62.6 \pm 4.5 \\
61.8\end{array}$ & $\begin{array}{l}\text { Ga. Soln. Calori. } T=1102 \mathrm{~K} \\
\text { Miedema's model }\end{array}$ & $\begin{array}{l}{[15]} \\
{[13]}\end{array}$ & -58513 \\
\hline $\mathrm{GaLa}_{3}$ & & & & -38636 \\
\hline
\end{tabular}




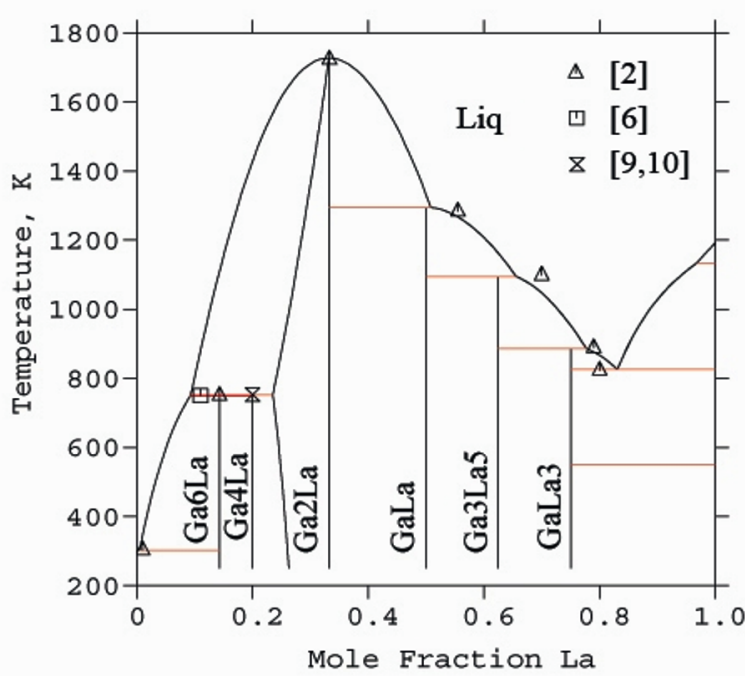

Fig. 2. Calculated Ga-La phase diagram with data from [2]

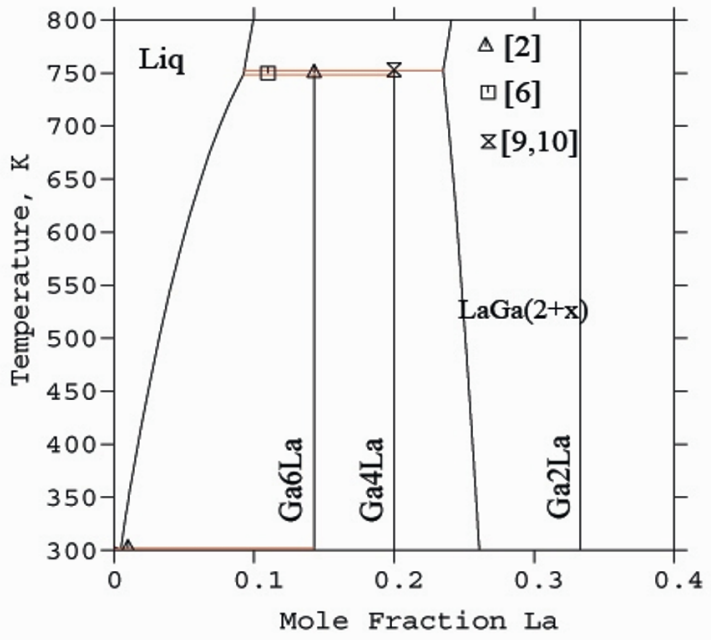

Fig. 3. Ga-rich region of the Ga-La phase diagram.

The assessed enthalpy of formation of $\mathrm{Ga}_{2} \mathrm{La}\left(\Delta H_{f}=-\right.$ $72882 \mathrm{~J} / \mathrm{mol}$ ) is in reasonable agreement with the experimental data $\left(\Delta H_{f}=-67500 \mathrm{~J} / \mathrm{mol}, \Delta H_{f}=-69200\right.$ $\mathrm{J} / \mathrm{mol}$ and $\Delta H_{f}=-69000 \mathrm{~J} / \mathrm{mol}$ ) determined in [13], [12] and [15]. The computed value of enthalpy of formation of $\mathrm{GaLa}\left(\Delta H_{f}=-77746 \mathrm{~J} / \mathrm{mol}\right)$ is in good agreement with the values determined by $[13,15]\left(\Delta H_{f}\right.$ $=-73500 \mathrm{~J} / \mathrm{mol}$ and $\Delta H_{f}=-74800 \mathrm{~J} / \mathrm{mol}$ ). For $\mathrm{Ga}_{3} \mathrm{La}_{5}$, the computed value is $-58513 \mathrm{~J} / \mathrm{mol}$, in reasonable agreement with the experimental data $\left(\Delta H_{f}=\right.$ $62600 \pm 4500 \mathrm{~J} / \mathrm{mol}$ and $\Delta H_{f}=-61800 \mathrm{~J} / \mathrm{mol}$ ) determined in [15] and [13]. As mentioned in [20], in order to check that the optimized thermodynamic parameters of the intermetallic compounds are satisfactory, we verified that, when the liquid phase is suspended during the calculation of the Ga-La phase diagram, the stoichiometric phases disappear at high temperatures and only the bcc_A2 solid solution is calculated on the whole La composition range and not the $\alpha \mathrm{Ga}$ one in the Ga-rich region. This is due to the power series in terms of temperature for the Ga element in the bcc A2 state which becomes metastable compared to the $\alpha \mathrm{Ga}$ state for higher temperatures [16].

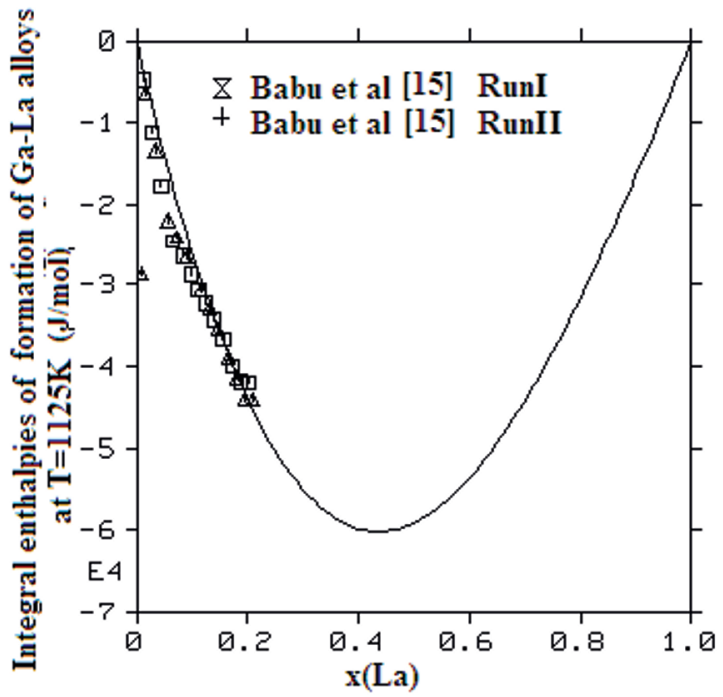

Fig. 4. Comparison of the calculated and measured integral enthalpy of formation of Ga-La alloys at $\mathrm{T}=1125 \mathrm{~K}$. The reference states were $\mathrm{Ga}$ and $\mathrm{La}$ liquid at $\mathrm{T}=1125 \mathrm{~K}$.

\section{Conclusion}

A thermodynamic assessment of the Ga-La system has been carried out. A consistent set of thermodynamic parameters has been derived. The computed values are in good agreement with the experimental thermodynamic and phase diagram data and we verified that no unwanted inverted miscibility gap was calculated for the solution phases up to $5000 \mathrm{~K}$.

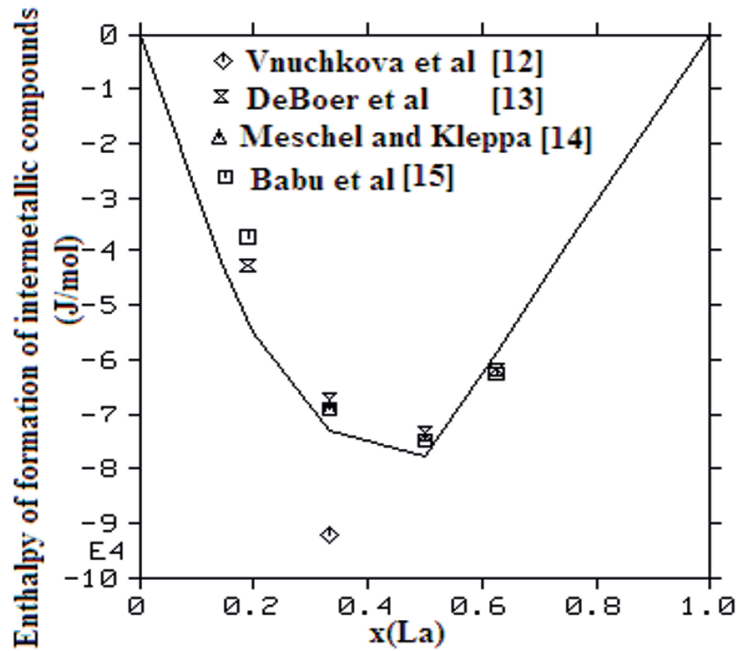

Fig. 5. Calculated and measured enthalpies of formation of the intermetallic compounds.

\section{References}

1. J.D. Shephard, R.I. Kangley , R.J. Hand, D. Furniss , C.A. Miller and A.B. Seddon, J. Non-Cryst. Solids 332, 271-278 (2003)

2. A. Palenzona, S. Cirafici, J. Phase Equilib. 11, 72-77 (1990) 
3. T.B. Massalski, H. Okamoto, P.R. Subramanian, and L. Kacprzak, Binary Alloys Phase Diagrams 2nd ed., ASM International, Materials Park, OH, 2, 1816-1818 (1990)

4. S.P. Yatsenko, J. Chim. Phys., 74 836-843 (1977)

5. S.P. Yatsenko, A.A. Semyannikov, B.G. Semenov, and K.A. Chuntonov, J. Less-Common Met., 64, 185-199. (1979)

6. J. Pelleg, G. Kimmel, and D. Dayan, J. Less- Common Met., 81, 33-44 (1981)

7. D. Dayan, U. Atzmony, and M.P Dariel, J. LessCommon Met., 87, 87-98 (1982)

8. L. Zevin, J. Pelleg, G. Kimmel and D. Dayan, Scr. Metall, 18, (1984) 1257.

9. G. Kimmel and W.P. Kaplan, Scr. Metall., 25571 (1991)

10. W.D. Kaplan and G. Kimmel, J. Less-Common Met., 232, 126-132 (1996)

11. S.S. Lu, S. Xie, and J. Liang, Acta Phys. Sin. 31, 1635$1641(1982)$
12. V.A. Vnuchkova, A.P. Bayanov and V.V. Serebrennikov, Russ. J. Phy. Chem. 45, 99 (1971)

13. F.R. De Boer, R. Boom, W.C.M. Mattens, A.R. Miedema and A.K. Niessen, Cohesion in Metals, Transition Metal Alloys, North-Holland, Amsterdam, (1998)

14. Meschel and O.J. Kleppa, J. Alloys Compds, 311,241247 (2000)

15. R. Babu , K. Nagarajan and V. Venugopal, J. Alloys Compds, 316, 124-130 (2001)

16. A.T. Dinsdale, Calphad, 15, 317 (1991)

17. O. Redlich and A. Kister, Ind. Eng. Chem, 40, 345 (1948)

18. B. Sundman and J-O. Andersson, CALPHAD 9, 153190 (1985)

19. L.Kaufman and H. Bernstein, Computer Calculations of Phase Diagrams, Academic Press, New-York, NY, (1970)

20. S.L. Chen, S. Daniel, F. Zhang, Y.A. Chang, W.A. Oates and R. Schmid-Fetzer, J. Phase Equilib. 22, 373$378(2001)$ 